\title{
A possible role for potassium and pyruvate in the modulation of sperm motility in the rabbit oviducal isthmus
}

\author{
L. J. Burkman*, J. W. Overstreet and D. F. Katz
}

Division of Reproductive Biology and Medicine, Department of Obstetrics and Gynecology, and Department of Human Anatomy, School of Medicine, University of California, Davis, California 95616, U.S.A.

\begin{abstract}
Summary. Spermatozoa were recovered from the isthmus of the rabbit oviduct at 4 and $11 \mathrm{~h}$ post coitum using several defined flushing media. The motility of spermatozoa in the isthmic flushings was subsequently analysed from video recordings. There was little sperm movement in the native isthmic fluid, but vigorous flagellar activity and hyperactivated movement were induced by flushing the isthmus with $0.25 \mathrm{M}$-sucrose, apparently an effect of dilution. Flushing with a complex culture medium resulted in similar stimulation of sperm movement.

When pyruvate was present in the medium, hyperactivated flagellar bending was stimulated, whereas these movements were virtually absent when glucose alone was present. The stimulating effect of dilution was less pronounced when the flushing medium contained $50 \mathrm{~mm}$-potassium. When the isthmus was flushed with media containing $50 \mathrm{mM}-\mathrm{K}^{+}$and the $\mathrm{K}^{+}$concentration was lowered to $5 \mathrm{~mm}$ during a washing procedure, large-amplitude flagellar movements were sequentially suppressed and restored. The restoration of large-amplitude movements was enhanced when pyruvate was present in the $5 \mathrm{~mm}-\mathrm{K}^{+}$washing medium. These results suggest that alterations in the concentration of both $\mathrm{K}^{+}$and pyruvate may have a role in regulating the motility of rabbit spermatozoa in the oviducal isthmus, $\mathrm{K}^{+}$being inhibitory and pyruvate stimulatory.
\end{abstract}

\section{Introduction}

There is evidence for sperm retention in the oviducal isthmus of the rabbit (Overstreet \& Cooper, 1975; Overstreet, Cooper \& Katz, 1978) as well as in other species (Overstreet, 1983). In the rabbit, biophysical and biochemical properties of the isthmus may impede the upward migration of spermatozoa and facilitate sperm storage. Important physical characteristics of the isthmus include the narrow isthmic lumen (Nilsson \& Reinius, 1969), a viscous isthmic mucus (Jansen \& Bajpai, 1982), reduced local temperatures (David, Vilensky \& Hilee, 1972), the pro-uterine ciliary beat (Gaddum-Rosse \& Blandau, 1973) and the oviducal muscular contractions which are directed primarily towards the uterus (Bourdage \& Halbert, 1980). In the rabbit, at least, there is an additional physiological interaction between the spermatozoa and the isthmic environment which involves the modulation of sperm motility. The relatively vigorous motility displayed by spermatozoa in the rabbit uterus is largely inhibited after residence for several hours in the lower

* Present address: Department of Obstetrics and Gynecology, VIP Program, Eastern Virginia Medical School, P.O. Box 1980, Norfolk, Virginia 23501, U.S.A. 
isthmus (Overstreet et al., 1978; Overstreet, Katz \& Johnson, 1980; Johnson, Katz \& Overstreet, 1981). Active swimming, however, can be readily induced by dilution of the isthmic contents with ampullary fluid or artificial media (Overstreet et al., 1980). Under some experimental conditions, the enhancement of isthmic sperm motility is associated with hyperactivated movement of the sperm flagellum (Johnson et al., 1981). The term 'hyperactivation' is now used to designate the type of sperm movement that was previously called 'activation' (Yanagimachi, 1981).

Hyperactivation of spermatozoa has been associated in several species with the completion of capacitation and the acrosome reaction in vitro (Yanagimachi, 1981). In the rabbit, this pattern of sperm movement is encountered primarily in the oviduct near the time of ovulation and may be instrumental in the final ascent of spermatozoa from the isthmic reservoir to the site of fertilization (Johnson et al., 1981; Suarez, Katz \& Overstreet, 1983).

Our previous experiments demonstrated that the composition of the flushing medium can significantly affect the motility of the isthmic sperm cells. Initially, rabbit isthmic spermatozoa were recovered in a serum Tyrode medium (Overstreet \& Cooper, 1975). The sluggish, subdued movements of these cells provided the first indication that sperm motility might be modulated in the oviducal environment. Similar initial sperm behaviour was recorded after the isthmic contents were flushed with rabbit ampullary fluid (Overstreet et al., 1980). In these latter experiments, the subdued motility of the isthmic spermatozoa was spontaneously converted to vigorous swimming during a 4-h period of incubation in vitro. When the complex in-vitro fertilization medium of Brackett \& Oliphant (1975) was used for sperm recovery from the isthmus, immediate vigorous motility was induced and many of the isthmic spermatozoa displayed hyperactivated movement (Overstreet et al., 1980). We have now investigated whether dilution of some inhibitory factor within the isthmic fluid and/or addition of a stimulatory component in the recovery media can induce vigorous sperm motility.

\section{Materials and Methods}

\section{Media and chemicals}

Two types of media were used (Table 1). A simple medium consisting principally of $0.25 \mathrm{M}$ crystalline sucrose (Grade I, Sigma Chemical Co., St Louis, MO, U.S.A.) was used in Exp. 1. The sucrose content in Medium 5 and Medium 6 (Exp. 3) was approximately $0 \cdot 106$ and $0 \cdot 199 \mathrm{M}$, respectively. The media used in Exp. 2 were based on the fertilization medium of Brackett \& Oliphant (1975). Bovine serum albumin (Fraction V) was obtained from Sigma; all other chemicals were of analytical grade.

\section{Recovery and observation of spermatozoa from the female tract; general procedures}

New Zealand White female rabbits (virgin and parous) were allowed 1-3 matings with 1 or 2 New Zealand White males. All males had previously sired a litter. At 4 or 11 h post coitum (p.c.), the female was killed by intravenous overdose of pentabarbitone sodium (Nembutal : Abbott). All subsequent manipulations and observations were carried out in a $37^{\circ} \mathrm{C}$ controlled-environment room.

The abdomen was opened and haemostat clamps were applied to isolate the lower isthmus of one or both oviducts (Overstreet \& Cooper, 1978). When two lower isthmic segments were removed, one was stored under a water-saturated atmosphere of $5 \% \mathrm{CO}_{2}$ in air until flushing. The duration of storage ranged from 30 to $75 \mathrm{~min}$; the choice of left versus right isthmus for delayed flushing was random. Each isthmus was flushed with the appropriate medium via the blunted needle of a Medi-wing infusion set (Sherwood Medical, St Louis, MO, U.S.A.), which was inserted into the ovarian end of the isthmic segment. The isthmic contents were collected into a capillary pipette (Clay Adams, Parsipannay, NJ, U.S.A.) held in the uterine end of the isthmus. The details of the flushing apparatus and methodology have been published previously (Overstreet \& Cooper, 
1978). After recovery, each sperm suspension was drawn into an optically clear, flat capillary tube (Microslide; Vitro Dynamics, Rockaway, NJ, U.S.A.). Paraffin oil was deposited at both ends of the fluid column to prevent evaporation.

Isthmic spermatozoa were recorded through the walls of the flat capillary tube using an Olympus inverted microscope with differential interference contrast optics, and equipped with an RCA 1000 black and white video camera ( $\times 40$ objective and $\times 2.5$ camera ocular). Videotape recordings were made on 0.5 inch VHS cassettes, using a Panasonic NV 8200 recorder. Sperm movements were recorded over $10-\mathrm{sec}$ intervals during a 5-10 min period. All motile spermatozoa seen were recorded up to a maximum of 40 spermatozoa.

\section{Experiments}

Experiment 1. To determine the effect of dilution on isthmic sperm motility, 4 females were killed at $4 \mathrm{~h}$ p.c. and another 4 animals at $11 \mathrm{~h}$ p.c. One isthmus from each animal was flushed with equilibrated mineral oil to recover the spermatozoa in the native isthmic fluid (Overstreet $e t$ al., 1980). Immediately after flushing, the contents of the capillary pipette (10 $\mu$ : Clay Adams) were expelled into a Petri dish under gas-equilibrated paraffin oil (Squibb). Approximately one half of

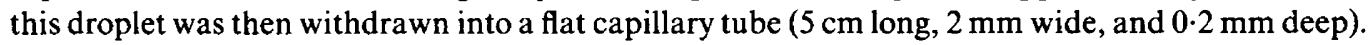
The contralateral isthmus was flushed with $10 \mu 10.25 \mathrm{M}$-sucrose solution (Table 1). The order of flushing was reversed in alternate experiments.

Table 1. Concentrations of specific constituents (mM), osmolality (mosmol), and $\mathrm{pH}$ of the flushing media used in these experiments

\begin{tabular}{|c|c|c|c|c|c|c|c|c|}
\hline Exp. & Medium & $\mathrm{pH}$ & mosmol & $\mathbf{K}^{+}$ & $\mathrm{Na}^{+}$ & Glucose & Pyruvate & $\mathrm{HCO}_{3}{ }^{-}$ \\
\hline 1 & $0.25 \mathrm{M}$-Sucrose & $6 \cdot 9-7 \cdot 1$ & 295 & 0 & 0 & 0 & 0 & 0 \\
\hline 2 & $\begin{array}{l}\text { Culture medium } 1^{*} \\
\text { Culture medium } 2 \\
\text { Culture medium } 3 \\
\text { Culture medium } 4\end{array}$ & $\begin{array}{l}7 \cdot 6-7 \cdot 8 \\
7 \cdot 6-7 \cdot 8 \\
7 \cdot 7-7.9 \\
7 \cdot 7-7 \cdot 9\end{array}$ & $\begin{array}{l}298 \\
298 \\
300 \\
300\end{array}$ & $\begin{array}{r}4 \\
4 \\
50 \\
50\end{array}$ & $\begin{array}{l}151 \\
150 \\
104 \\
105\end{array}$ & $\begin{array}{l}14 \\
14 \\
14 \\
14\end{array}$ & $\begin{array}{l}1 \cdot 3 \\
0 \\
0 \\
1 \cdot 3\end{array}$ & $\begin{array}{l}37 \\
37 \\
37 \\
37\end{array}$ \\
\hline 3 & $\begin{array}{l}\text { Buffered sucrose } \nmid \\
\text { medium } 5 \\
\text { medium } 6 \\
\text { medium } 7\end{array}$ & $\begin{array}{l}7 \cdot 4-7 \cdot 5 \\
7 \cdot 5-7 \cdot 7 \\
7 \cdot 5-7 \cdot 7\end{array}$ & $\begin{array}{l}300 \\
300 \\
300\end{array}$ & $\begin{array}{r}50 \\
5 \\
5\end{array}$ & $\begin{array}{l}50 \ddagger \\
50 \\
50\end{array}$ & $\begin{array}{l}5 \\
5 \\
5\end{array}$ & $\begin{array}{r}0 \\
0 \\
10\end{array}$ & $\begin{array}{l}30 \\
30 \\
30\end{array}$ \\
\hline
\end{tabular}

* The culture media were based on the in-vitro fertilization medium of Brackett \& Oliphant (1975) and included $\mathrm{CaCl}_{2}, \mathrm{MgCl}_{2}, \mathrm{NaH}_{2} \mathrm{PO}_{4}$, sodium penicillin- $\mathrm{G}$ and bovine serum albumin.

† These media included $20 \mathrm{~mm}$-sodium Hepes as a second buffer and $0.072 \mathrm{~mm}$-sodium penicillin-G.

† The bicarbonate and Hepes buffers provided the $50 \mathrm{~mm}$-sodium.

Experiment 2. To investigate which components of a complex flushing medium might stimulate or suppress sperm movement, experiments were carried out using culture media based on the formula of Brackett \& Oliphant (1975). Four isthmi from different females were flushed at 4-5 h p.c. with the complete medium containing $4 \mathrm{~mm}$-potassium and 1.3 mm-pyruvate (Medium 1, Table 1). Three isthmi from 3 females were flushed with the same medium but without pyruvate (Medium 2). Nine isthmi from 5 animals were flushed with a pyruvate-free, $50 \mathrm{~mm}$-potassium medium (Medium 3), and three isthmi from 3 animals received the same high-potassium medium but containing pyruvate (Medium 4). The $50 \mu$ l flushing of each isthmus was collected in fire-polished capillary tubes ( $100 \mu \mathrm{l}$ volume), using the normal flushing technique. The sperm suspension was then injected directly into the lumen of a $0.4 \mathrm{~mm}$ flat capillary tube $(5 \mathrm{~cm}$ long, $4 \mathrm{~mm}$ wide and 0.4 mm deep).

Experiment 3. In these experiments, the behaviour of isthmic spermatozoa was examined after sequential exposure to media of altered potassium and pyruvate content. To minimize the number 
of factors contributing biochemically to the sperm behaviour, we chose to use the simple sucrosebased medium shown in Table 1. Because of the longer duration of sperm manipulation and observation in these experiments, the sucrose media were buffered with Hepes and bicarbonate, and supplemented with glucose. Preliminary experiments showed that neither the bicarbonate ion nor glucose was a stimulant of isthmic sperm motility (data not shown). Six females were killed at $4 \mathrm{~h}$ p.c.; one isthmus per animal was flushed with the $50 \mathrm{~mm}$-potassium buffered-sucrose medium (Medium 5, Table 1) in an attempt to recover the spermatozoa in a state of subdued movement. The flushings $(50 \mu \mathrm{l})$ were immediately loaded into a microperfusion chamber on the stage of the inverted microscope.

With the aid of this microperfusion chamber, continuous observations of sperm movement could be made before, during and after a change in composition of the suspending medium. Details of the design and operation of the chamber have been published elsewhere (Burkman \& Overstreet, 1984). Its essential components include a flat, glass capillary tube $(0.4 \mathrm{~mm}$ deep $)$ attached at either end to a lucite filter assembly housing a Millipore disc $(1 \cdot 2 \mu \mathrm{m}$ pore size). After loading the sperm suspension, a $0.3 \mathrm{ml}$ perfusate was delivered through the chamber (maximum current velocity was $50 \mu \mathrm{m} / \mathrm{sec}$ ) using a Harvard infusion pump fitted with a $1 \mathrm{ml}$ syringe. This resulted in a 2 -fold exchange of the fluid contents in the chamber while minimizing any physical trauma to the sperm cells.

In each replicate experiment, the movements of 10-20 spermatozoa in the isthmic flushings were recorded on videotape immediately after the chamber was loaded. The fluid content of the chamber was then replaced with a second medium, and the movements of 20-30 spermatozoa were similarly recorded. In 3 replicate experiments, the potassium content of the second medium was reduced to $5 \mathrm{mM}$ (Medium 6) while in 3 other experiments, the $5 \mathrm{~mm}$-potassium medium was supplemented with $10 \mathrm{mM}$-pyruvate (Medium 7).

\section{Analysis of sperm movement characteristics from video recordings}

The videotapes were analysed on a television monitor (Electrohome, $30.5 \mathrm{~cm}$ diagonal screen). The swimming speeds of individual spermatozoa were measured by applying a transparent overlay with concentric circles to the video screen. The tape was played forward for 0.5 or $1 \mathrm{sec}$ and the approximate straight-line distance travelled by the head-midpiece junction was determined (Katz \& Overstreet, 1981).

In our previous studies with high-speed cinemicrography, we used a flagellar beat frequency of $18 \mathrm{~Hz}$ to demarcate the more vigorous, faster beating sperm cells from the weaker ones (Johnson $e t$ al., 1981). In the present study, the proportion of spermatozoa in this high-frequency group was determined with a Wavetek frequency generator. While viewing the videotaped sperm image in real time, the visually perceived beat frequency was compared with the $18 \mathrm{~Hz}$ train of audible pulses from the frequency generator. Preliminary experiments showed that the percentage of highfrequency spermatozoa determined by this method compared favourably with those obtained via frame-by-frame analysis of high-speed videotapes (38 compared with $30 \%, \mathrm{~N}=50, P>0 \cdot 50, \chi^{2}$ analysis). At very low beat frequencies $(\leq 5 \mathrm{~Hz})$ this method facilitated the direct estimation of beat frequency.

Spermatozoa displaying continuous, large-amplitude flagellar beating with high curvature of the midpiece were classified as hyperactivated, and their proportion in the population was determined. The flagellar movements of many other spermatozoa were characterized by a single or several large amplitude beats which were superimposed on the regular, lower amplitude beating pattern. These secondary beats kinematically resembled the large amplitude beats of hyperactivated spermatozoa, and in the present work we have interpreted this pattern as representing an intermediate state between preactivated and hyperactivated movement (Johnson et al., 1981). Such movement is designated as 'transitional beating'. 


\section{Statistics}

Within experiments, data for individual treatments were pooled over animals. Student's $t$ test was used to compare mean swimming speeds. The significance of differences in the percentages of spermatozoa with high-frequency flagellation, hyperactivated movement and transitional movement was determined using $\chi^{2}$ analysis $(2 \times 2$ contingency tables; Snedecor \& Cochran, 1973).

\section{Results}

\section{Experiment 1: effects of simple dilution on isthmic sperm movement}

When the isthmic contents were recovered in mineral oil at 4 or $11 \mathrm{~h}$ p.c. (Table 2), there was no evidence of forward movement in the sperm population. The mean \pm s.e.m. beat frequency of isthmic spermatozoa in their native fluid was estimated with the Wavetek generator to be $4.5 \pm 0.3$ $\mathrm{Hz}(n=21$, data pooled over time). The mean beat frequencies for spermatozoa recovered at 4 and $11 \mathrm{~h}$ p.c. were not significantly different, (data not shown). Although a total of $38 \%$ of the spermatozoa showed hyperactivated or transitional movements, the frequency of the largeamplitude movements was always less than $1 \mathrm{beat} / \mathrm{sec}$.

Table 2. Movement characteristics of rabbit spermatozoa (no. in parentheses) recovered from the oviducal isthmus in their native fluid ( 4 and $11 \mathrm{~h}$ p.c.) or in $0.25 \mathrm{M}$-sucrose in water $(4 \mathrm{~h} \mathrm{p.c.)}$

\begin{tabular}{|c|c|c|c|c|}
\hline \multirow{3}{*}{$\begin{array}{l}\text { Suspending } \\
\text { medium }\end{array}$} & \multirow{3}{*}{$\begin{array}{c}\text { Mean } \pm \text { s.e.m. swimming } \\
\text { speed }(\mu \mathrm{m} / \mathrm{sec})\end{array}$} & \multicolumn{3}{|c|}{ Percentage of motile spermatozoa exhibiting: } \\
\hline & & \multirow{2}{*}{$\begin{array}{c}\text { High-frequency } \\
\text { flagellar }(\geq 18 \mathrm{~Hz}) \\
\text { beats }\end{array}$} & \multicolumn{2}{|c|}{ Large-amplitude beats } \\
\hline & & & Hyperactivated & Transitional \\
\hline Native isthmic fluid $\uparrow$ & $0(21)$ & $0(21)$ & $19(21)$ & $19(21)$ \\
\hline $0.25 \mathrm{M}$-sucrose & $* * * 31.9 \pm 4(27)$ & **30(46) & *47 (97) & $14(97)$ \\
\hline
\end{tabular}

+ Data pooled for $4 \mathrm{~h}$ and $11 \mathrm{~h}$ p.c.

Significantly different from values for spermatozoa in native isthmic fluid: ${ }^{*} P<0.02 ;{ }^{* *} P<0.01$; $* * * P<0.001$.

Flushing the isthmus with $0.25 \mathrm{M}$-sucrose resulted in sperm movements of greatly increased vigour (Table 2). The average percentage motility in these sperm suspensions was $79 \%$ (range $65-$ $90 \%$ ). The mean swimming speed increased to $32 \mu \mathrm{m} / \mathrm{sec}$ and $30 \%$ of the isthmic spermatozoa had beat frequencies $\geq 18 \mathrm{~Hz}$ (Table 2 ). Hyperactivated movement was exhibited by $47 \%$ of the spermatozoa but the incidence of transitional movement did not change. The beat frequencies of all large-amplitude movements were conspicuously higher after dilution with sucrose, and estimated to be $4.5 \pm 0.8 \mathrm{~Hz}(n=45)$ with the Wavetek generator.

\section{Experiment 2: effect of potassium and pyruvate on isthmic sperm motility}

When isthmic spermatozoa were recovered in the complex culture medium (Table 3, Medium 1), the sperm movement characteristics were not significantly different from those observed after flushing with a simple sucrose-based medium (Table 2). However, mean swimming speeds, flagellar beat frequencies and the incidence of hyperactivated movement were all significantly reduced when pyruvate was omitted from the recovery medium (Table 3, Medium 2), although the incidence of transitional movement increased. When the potassium concentration was increased to $50 \mathrm{~mm}$ (Medium 3), the mean swimming speed and flagellar beat frequency showed no further reduction, but the incidence of hyperactivated and transitional movements was significantly lower (Table 3, Medium 2 versus Medium 3). With the addition of pyruvate to the high-potassium medium (Medium 4), the incidence of transitional movements was improved but all other values remained depressed (Table 3 ). 
Table 3. The movement characteristics of rabbit spermatozoa (no. in parentheses) recovered from the oviducal isthmus at $4 \mathrm{~h}$ p.c. with defined culture media

\begin{tabular}{|c|c|c|c|c|}
\hline \multirow[b]{3}{*}{ Flushing medium* } & \multirow{3}{*}{$\begin{array}{c}\text { Mean } \pm \text { s.e.m. swimming } \\
\text { speed }(\mu \mathrm{m} / \mathrm{sec})\end{array}$} & \multicolumn{3}{|c|}{ Percentage of motile spermatozoa exhibiting: } \\
\hline & & \multirow{2}{*}{$\begin{array}{c}\text { High-frequency } \\
\text { flagellar }(\geq 18 \mathrm{~Hz}) \\
\text { beats }\end{array}$} & \multicolumn{2}{|c|}{ Large-amplitude beats } \\
\hline & & & Hyperactivated & Transitional \\
\hline $\begin{array}{l}\text { Medium 1 } \\
\quad \text { (complete) }\end{array}$ & $36.7 \pm 6.9^{a}(9)$ & $27^{a}(48)$ & $51^{a}(61)$ & $18^{\mathrm{a}}(61)$ \\
\hline $\begin{array}{l}\text { Medium } 2 \\
\quad \text { (without pyruvate) }\end{array}$ & $6.8 \pm 1.4^{\mathrm{b}}(33)$ & $0^{\mathrm{b}}(64)$ & $11^{\mathrm{b}}(64)$ & $42^{b}(64)$ \\
\hline $\begin{array}{l}\text { Medium } 3 \\
\text { (high potassium } \\
\text { without pyruvate) }\end{array}$ & $6.2 \pm 0.8^{b}(71)$ & $0^{\mathrm{b}}(204)$ & $2^{c}(215)$ & $10^{\mathrm{ac}}(215)$ \\
\hline $\begin{array}{l}\text { Medium } 4 \\
\text { (high potassium } \\
\text { plus pyruvate) }\end{array}$ & $9 \cdot 2 \pm 1 \cdot 1^{b}(22)$ & $2^{b}(62)$ & $2^{b c}(63)$ & $38^{b}(63)$ \\
\hline
\end{tabular}

* The basic compositions of the media are given in Table 1.

Within columns, values without a common superscript letter are significantly different, $P<0.005$.

\section{Experiment 3: observations of isthmic spermatozoa in the microperfusion chamber}

These experiments demonstrated that the potassium-mediated suppression of large-amplitude flagellar movements could be significantly reversed when the potassium concentration in the medium was lowered even in the absence of pyruvate. After the 50 mm-potassium medium (Medium 5) was exchanged for 5 mM-potassium (Medium 6), the percentage of spermatozoa with hyperactivated movement increased nearly 3 -fold (Table 4). There was a concomitant reduction in the percentage of spermatozoa exhibiting transitional movement and so the total value for all large-amplitude movements was unchanged. When the $5 \mathrm{~mm}$-potassium washing medium was supplemented with $10 \mathrm{~mm}$-pyruvate (Medium 7), there was again a stimulation of hyperactivated movement, but it was accompanied by an increase in the percentage of spermatozoa with transitional movement (Table 4). Although the trends were the same, the response of lower isthmic

Table 4. Movement characteristics of rabbit spermatozoa (no. in parentheses) recovered from the oviducal isthmus at $4 \mathrm{~h} \mathrm{p.c.} \mathrm{and}$ observed in a microperfusion chamber before and after a change of the suspending medium

\begin{tabular}{|c|c|c|c|}
\hline \multirow[b]{3}{*}{ Suspending medium* } & \multicolumn{3}{|c|}{ Percentage of motile spermatozoa exhibiting: } \\
\hline & \multirow{2}{*}{$\begin{array}{c}\text { High-frequency } \\
\text { flagellar }(\geq 18 \mathrm{~Hz}) \\
\text { beats }\end{array}$} & \multicolumn{2}{|c|}{ Large-amplitude beats } \\
\hline & & Hyperactivated & Transitional \\
\hline \multicolumn{4}{|l|}{ Recovery medium: } \\
\hline Medium $5\left(50 \mathrm{mM}-\mathrm{K}^{+}\right)$ & $7(87)$ & $12(100)$ & $32(100)$ \\
\hline \multicolumn{4}{|l|}{ Washing medium: } \\
\hline Medium $6\left(5 \mathrm{~mm}-\mathrm{K}^{+}\right)$ & $15(54)$ & $\dagger 35(65)$ & $+10(65)$ \\
\hline \multicolumn{4}{|l|}{ Recovery medium: } \\
\hline Medium $5\left(50 \mathrm{~mm}-\mathrm{K}^{+}\right)$ & $10(104)$ & $12(107)$ & $29(107)$ \\
\hline \multicolumn{4}{|l|}{ Washing medium: } \\
\hline Medium $7\left(5 \mathrm{~mm}-\mathrm{K}^{+}\right)$ & $16(93)$ & $\ddagger 25(103)$ & $\ddagger 47(103)$ \\
\hline
\end{tabular}


spermatozoa to $50 \mathrm{~mm}$-potassium was not identical in Exps 2 and 3. This probably resulted from the different $\mathrm{pHs}$ and/or chemical compositions of the two media, but the precise reason was not investigated in these experiments.

\section{Discussion}

Spermatozoa recovered from the lower isthmus in their native fluid showed no forward movement. The mean frequency of their flagellar beat was very low and the fiagellar amplitude small. Simple dilution of the isthmic contents with a sucrose solution resulted in vigorous flagellar movements and the hyperactivation of approximately half of the motile spermatozoa. The hyperactivated movements of diluted isthmic spermatozoa were very similar but not identical to the movements of spermatozoa recovered in native fluid from the rabbit ampulla (Suarez et al., 1983). The flagellar beat frequencies of hyperactivated isthmic spermatozoa were significantly lower than those observed for ampullary spermatozoa. However, the geometries of the swimming trajectories for the two populations were quite similar. These apparent differences in 'hyperactivated' movement by isthmic and ampullary spermatozoa should not be surprising since experimental conditions in vitro (Overstreet et al., 1980; Johnson et al., 1981 ; present study) cannot duplicate events occurring in the oviduct during sperm transport to the site of fertilization.

The stimulating effect of dilution was much less dramatic when the flushing medium contained high concentrations of potassium. When pyruvate was present in the medium, large-amplitude fiagellar bending was stimulated, whereas these movements were virtually absent when glucose alone was present. Large-amplitude, high-curvature bending of the sperm flagellum returned as the potassium concentration was lowered during a washing procedure. Restoration of large-amplitude movement, however, was even more effective when pyruvate was present in the low-potassium washing medium.

In Exp. 1, we were able to quantitate the motility of the barely moving isthmic spermatozoa in their native fluid, thus verifying our earlier subjective impressions based on visual microscopic studies (Overstreet et al., 1980) and videomicrographic tape recordings (Johnson et al., 1981). The extent of this motility reduction is striking when contrasted with the vigorous movements of uterine spermatozoa in the native fluid (mean swimming speed at $4 \mathrm{~h} p . c .=19.6 \pm 3.0 \mu \mathrm{m} / \mathrm{sec}, n=31$, and a mean flagellar beat frequency more than double the value seen in the native isthmic suspension; Burkman, 1983).

The initial design of these experiments was based on the hypothesis that specific components in the recovery media were responsible for the 'stimulation' of isthmic sperm motility which follows dilution of the isthmic contents. However, a simple sucrose medium, without additional ions or substrates, was a highly effective stimulator of isthmic sperm movement; the movement characteristics for isthmic spermatozoa in simple sucrose medium were statistically indistinguishable from the values seen for spermatozoa recovered in the complete culture medium (Medium 1). Of the spermatozoa recovered in sucrose, $61 \%$ displayed large-amplitude movements in comparison with $38 \%$ in the native fluid. Therefore, dilution appeared to stimulate large-amplitude flagellar bending in spermatozoa which previously had poor motility.

Spermatozoa cannot metabolize sucrose. Therefore, these observations suggest that the depression of isthmic sperm motility may be accomplished by the presence of one or more motility inhibitors in the isthmic environment. A similar suppression of sperm movement may take place in the epididymal lumen of the rat and rabbit (Storey, 1975; Turner, D'Addario \& Howards, 1978). Elevated viscoelasticity of the epididymal plasma may play a role in the suppression of sperm motility in the rat epididymis (Usselman \& Cone, 1981). The lower isthmus of the rabbit oviduct is reported to contain a viscous luminal mucus (Jansen, 1978). However, if the suppression of sperm motility in the rabbit isthmus were purely biophysical, one would expect immediate stimulation of sperm motility after dilution. Since diluted isthmic spermatozoa require several minutes for the 
evolution of vigorous movement (Johnson et al., 1981), biochemical mechanisms must also be involved.

There is ample reason to suspect that the potassium ion $\left(\mathrm{K}^{+}\right)$could be involved in the inhibition of isthmic sperm motility. There appears to be an association between high $\mathrm{K}^{+}$levels in the epididymal plasma and inhibited epididymal sperm movement. Potassium concentrations much higher than those in blood plasma have been reported in the caput and/or cauda fluids of the hamster (39.3 mM; Jessee \& Howards, 1976), the elephant (64.8 mM; Jones, 1980), the bull (43.7 mM; Wales, Wallace \& White, 1966), the rat (54 mM; Pholpramool \& Chaturapanich, 1979) and the rabbit (24.8 $\mathrm{mM}$ in the cauda; Jones \& Glover, 1973). Boender (1976) showed that boar sperm motility was depressed in media with $45-135 \mathrm{~mm}-\mathrm{K}^{+}$and that the motility was restored by washing the same spermatozoa in a medium containing $5 \mathrm{~mm}-\mathrm{K}^{+}$. Similarly, quiescence was induced in seaurchin spermatozoa by increasing the $\mathrm{K}^{+}$levels in the surrounding medium (Gibbons, 1980). Fraser (1983) has reported that hyperactivated motility of mouse spermatozoa is reduced after incubation in iso-osmolal high potassium media $\left(27 \cdot 7 \mathrm{mM}-\mathrm{K}^{+}\right)$.

Potassium concentrations in oviducal fluids are not known with certainty. Elemental analysis of oviducal fluid from mice and women, obtained by micropuncture, showed $\mathrm{K}^{+}$concentrations to be as high as 28-29 mM (Roblero, Biggers \& Lechene, 1976; Borland, Hazra, Biggers \& Lechene, 1977; Borland, Biggers, Lechene \& Taymor, 1980). We have carried out preliminary studies by neutron probe analysis of $\mathrm{K}^{+}$concentrations in cell-free fluid obtained from the rabbit oviduct and uterus by flushing with mineral oil (Burkman, 1983). These results indicate that $\mathrm{K}^{+}$levels are $30.0 \pm 3 \mathrm{mM}$ in the lower isthmus at $11 \mathrm{~h}$ p.c., $29.6 \mathrm{mM}$ in the ampullary fluid at $4 \mathrm{~h}$ p.c., and $6.8 \pm 0.7 \mathrm{mM}$ in the uterine fluid ( 4 and $11 \mathrm{~h}$ p.c.). We do not know how much the $\mathrm{K}^{+}$levels may vary within oviducal compartments between the time of mating and ovulation.

In the present experiments, a minimal medium containing $50 \mathrm{~mm}-\mathrm{K}^{+}$effectively depressed the beat frequencies and large-amplitude movement of lower isthmic spermatozoa. When the same population of spermatozoa was sequentially exposed to $50 \mathrm{mM}$ and then $5 \mathrm{~mm}-\mathrm{K}^{+}$, the incidence of hyperactivated movement increased as the $\mathrm{K}^{+}$concentration was lowered. Under these conditions, the distribution of spermatozoa with large-amplitude bending appeared to change between the hyperactivated and transitional categories; before and after the washing procedure, the total incidence of large-amplitude movements was $44-45 \%$. It appears, therefore, that many spermatozoa with the transitional movement pattern began to exhibit hyperactivated movement as the external potassium concentration declined.

The total percentage of large-amplitude movements (hyperactivated and transitional) increased significantly when the second, low-potassium medium contained pyruvate. When pyruvate was removed from the culture medium (Exp. 2, Medium 2), the reduced sperm motility was similar to that seen in serum Tyrode (Overstreet et al., 1978) and in fresh ampullary fluid (Overstreet et al., 1980). These data support our premise that alterations in the concentrations of both $\mathrm{K}^{+}$and pyruvate may have a role in regulating the motility of lower isthmic spermatozoa in the rabbit, $\mathrm{K}^{+}$ being inhibitory and pyruvate acting as a stimulant. These data are also consistent with the incidence of transitional large-amplitude beats observed in Exp. 2, for which pyruvate also appeared to be required (Table 3, Media 3 and 4).

It is likely that the suppressive action of the lower isthmus requires several hours to develop fully in vivo. Lower isthmic spermatozoa from the rabbit are still vigorous when recovered at $1.5 \mathrm{~h} \mathrm{p.c.,}$ but show subdued motility at 4 and $6 \mathrm{~h} \mathrm{p.c.} \mathrm{(Overstreet} \mathrm{et} \mathrm{al.,} \mathrm{1978).} \mathrm{Once} \mathrm{fully} \mathrm{established,}$ however, the suppressive effect of the isthmic environment must act quickly to alter sperm motility: the isthmic reservoir continues to fill between 4 and $6 \mathrm{~h}$ p.c., but the sperm populations recovered at these times are relatively homogeneous and have uniformly subdued motility (Overstreet et al., 1978). Spermatozoa recovered from the rabbit uterus at $4 \mathrm{~h}$ p.c. were not significantly affected by dilution or washing with a culture medium containing $50 \mathrm{mM}-\mathrm{K}^{+}$, even though exposure continued for $1 \mathrm{~h}$ (Burkman, 1983). Therefore, the physiological state of rabbit isthmic spermatozoa must enhance their sensitivity to $\mathrm{K}^{+}$or, alternatively, the presence of the 
potassium ion may act to augment or sustain a depression of flagellar activity induced by some other mechanism.

Our present experiments suggest that pyruvate may be a necessary substrate for rapid generation of hyperactivated movement of rabbit spermatozoa following isthmic quiescence. In the rabbit, the energetics of glucose metabolism appear to be insufficient to support such immediate hyperactivation. There is evidence that the metabolism of epididymal rabbit spermatozoa is more effectively stimulated by exogenous pyruvate in comparison with the relatively low levels of endogenous pyruvate which are derived from glucose (Storey, 1975). In this regard, the addition of pyruvate to the culture medium in Exp. 2 (Table 3, Medium 2) converted spermatozoa with intermittent large-amplitude beats into cells exhibiting continuous ones, i.e. expending more energy. Spermatozoa from the rabbit isthmus are not immediately vigorous when recovered in ampullary fluid (Overstreet et al., 1980), perhaps as a consequence of a relatively slow or delayed conversion of glucose or lactate to pyruvate. In contrast, when isthmic spermatozoa were recovered in media containing $1.3 \mathrm{~mm}$-pyruvate, they displayed immediate vigour and hyperactivated movement (Overstreet et al., 1980; Johnson et al., 1981 ; present study). This medium may bypass a ratelimiting, lactate-to-pyruvate conversion by supplying pyruvate directly.

Although they are self-consistent, these several hypotheses do not account for the rapid stimulation of hyperactivated movement after dilution of the isthmic contents with a simple sucrose solution. Clearly, additional intracellular events must occur in spermatozoa released from the isthmic environment. As our understanding of this complexity improves, additional insights into the physiology of sperm-oviducal interactions will emerge.

This work was supported by NIH Research Grants HD11186 and HD12971. A Research Career Development Award from NIH to J.W.O. (HD00224) is also acknowledged.

\section{References}

Boender, J. (1976) The effects of $\mathrm{Na}^{+}, \mathrm{K}^{+}$and ouabain on the motility and ATP content of boar spermatozoa. Proc. K. ned. Akad. Wet., Series C 79, 1333.

Borland, R.M., Hazra, S., Biggers, J.D. \& Lechene, C.P. (1977) The elemental composition of the environments of the gametes and preimplantation embryo during the initiation of pregnancy. Biol. Reprod. 16, $147-157$.

Borland, R.M., Biggers, J.D., Lechene, C.P. \& Taymor, M.L. (1980) Elemental composition of fluid in the human Fallopian tube. J. Reprod. Fert. 58, 479-482.

Bourdage, R.J. \& Halbert, S.A. (1980) In-vivo recording of oviductal contractions in rabbits during the periovulatory period. Am. J. Physiol. 239, 332-336.

Brackett, B.G. \& Oliphant, G. (1975) Capacitation of rabbit spermatozoa in vitro. Biol. Reprod. 12, 260-274.

Burkman, L.J. (1983) Physiology of rabbit oviductal spermatozoa. Ph.D. thesis, University of California, Davis.

Burkman, L.J. \& Overstreet, J.W. (1984) A microperfusion chamber for study of mammalian spermatozoa. Gamete Res. (In press).

David, A., Vilensky, A. \& Hilee, N. (1972) Temperature changes in the different parts of the rabbit's oviduct. Int. J. Gynec. Obstet. 10, 52-56.

Fraser, L.R. (1983) Potassium ions modulate expression of mouse sperm fertilizing ability, acrosome reaction and hyperactivated motility in vitro. J. Reprod. Fert. 69, 539-553.
Gaddum-Rosse, P. \& Blandau, R.J. (1973) In-vitro studies on ciliary activity within the oviducts of the rabbit and pig. Am. J. Anat. 136, 91-104.

Gibbons, B. (1980) Intermittent swimming in live sea urchin sperm. J. Cell Biol. 84, 1-12.

Jansen, R.P.S. (1978) Fallopian tube isthmic mucus and ovum transport. Science, N.Y. 201, 349-351.

Jansen, R.P.S. \& Bajpai, V.K. (1982) Oviduct acid mucus glycoproteins in the estrous rabbit. Ultrastructure and histochemistry. Biol. Reprod. 26, 155-168.

Jessee, S.J. \& Howards, S.S. (1976) A survey of sperm potassium and sodium concentrations in the tubular fluid of the hamster epididymis. Biol. Reprod. 15, 626-631.

Johnson, L.L., Katz, D.F. \& Overstreet, J.W. (1981) The movement characteristics of rabbit spermatozoa before and after activation. Gamete Res. 4, 275-282.

Jones, R. \& Glover, T.D. (1973) The collection and composition of epididymal plasma from the cauda epididymidis of the rabbit. J. Reprod. Fert. 34, 395403.

Jones, R.C. (1980) Luminal composition and maturation of spermatozoa in the genital ducts of the African elephant (Loxodonta africana). J. Reprod. Fert. 60, 87-93.

Katz, D.F. \& Overstreet, J.W. (1981) Sperm motility assessment by videomicrography. Fert. Steril. 35, $188-193$.

Nilsson, O. \& Reinius, S. (1969) Light and electron microscopic structure of the oviduct. In The Mammalian 
Oviduct, pp. 57-84. Eds E. S. E. Hafez \& R. J. Blandau. University of Chicago Press.

Overstreet, J.W. (1983) Transport of gametes in the reproductive tract of the female mammal. In Mechanism and Control of Animal Fertilization, pp. 499-543. Ed. J. F. Hartmann. Academic Press, New York.

Overstreet, J.W. \& Cooper, G.W. (1975) Reduced sperm motility in the isthmus of the rabbit oviduct. Nature, Lond. 258, 718-719.

Overstreet, J.W. \& Cooper, G.W. (1978) Sperm transport in the reproductive tract of the female rabbit. $I$. The rapid transit phase of transport. Biol. Reprod. 19, 101-114.

Overstreet, J.W., Cooper, G.W. \& Katz, D.F. (1978) Sperm transport in the reproductive tract of the female rabbit. II. The sustained phase of transport. Biol. Reprod. 19, 115-132.

Overstreet, J.W., Katz, D.F. \& Johnson, L.L. (1980) Motility of rabbit spermatozoa in the secretions of the oviduct. Biol. Reprod. 22, 1083-1088.

Pholpramool, C. \& Chaturapanich, G. (1979) Effect of sodium and potassium concentrations and $\mathrm{pH}$ on the maintenance of motility of rabbit and rat epididymal spermatozoa. J. Reprod. Fert. 57, 245-251.

Roblero, L., Biggers, J.D. \& Lechene, C.P. (1976) Electron probe analysis of the elemental micro- environment of oviductal mouse embryos. J. Reprod. Fert. 46, 431-434.

Snedecor, G.W. \& Cochran, W.G. (1973) Statistical Methods, 3rd edn. Iowa State University Press, Ames.

Storey, B.T. (1975) Energy metabolism of spermatozoa. IV. Effect of calcium on respiration of mature epididymal sperm of the rabbit. Biol. Reprod. 13, 1-9.

Suarez, S.S., Katz, D.F. \& Overstreet, J.W. (1983) Movement characteristics and acrosomal status of rabbit spermatozoa recovered at the site and time of fertilization. Biol. Reprod. 29, 1277-1287.

Turner, T.T., D'Addario, D. \& Howards, S.S. (1978) Further observations on the initiation of sperm motility. Biol. Reprod. 19, 1095-1101.

Usselman, M.C. \& Cone, R.A. (1981) Rat sperm are immobilized by the high viscoelasticity of cauda epididymal fluid. Biol. Reprod. 24, Suppl. 1, 45a, abstr.

Wales, R.G., Wallace, J.C. \& White, I.G. (1966) Composition of bull epididymal and testicular fluid. J. Reprod. Fert. 12, 139-144.

Yanagimachi, R. (1981) Mechanisms of fertilization in mammals. In Fertilization and Embryonic Development In Vitro, Ch. 5, pp. 81-182. Eds L. Mastroianni, Jr \& J. D. Biggers. Plenum Press, New York.

Received 9 August 1983 